\title{
Reaching proficiency in laparoscopic splenectomy
}

\author{
Tarik Zafer Nursal, Ali Ezer, Sedat Belli, Alper Parlakgumus, Kenan Caliskan, Turgut Noyan
}

Tarik Zafer Nursal, Ali Ezer, Sedat Belli, Alper Parlakgumus, Kenan Caliskan, Turgut Noyan, Department of General Surgery, University of Baskent, Dadaloglu Mah., 01200, Serin Evler 39. Sk. No. 6 Yüregir/Adana, Turkey

Author contributions: Nursal TZ and Ezer A contributed equally to this work; Nursal TZ, Ezer A, Belli S, Parlakgumus A, Caliskan $\mathrm{K}$ and Noyan $\mathrm{T}$ designed the research; Nursal TZ performed the research and analyzed the data; Caliskan K, Noyan T, Belli S contributed analytic tools; Nursal TZ and Ezer A wrote the paper.

Correspondence to: Dr. Ali Ezer, Department of General Surgery, University of Baskent, Dadaloglu Mah., 01200, Serin Evler 39. Sk. No. 6 Yüregir/Adana,

Turkey.draliezer@yahoo.com

Telephone: +90-535-9661344 Fax: +90-322-3271273

Received: June 2, 2009 Revised: July 10, 2009

Accepted: July 17, 2009

Published online: August 28, 2009

\section{Abstract}

AIM: To investigate the proficiency level reached in laparoscopic splenectomy using the learning curve method.

METHODS: All patients in need of splenectomy for benign causes in whom laparoscopic splenectomy was attempted by a single surgeon during a time period of 6 years were included in the study $(n=33)$. Besides demographics, operation-related variables and the response to surgery were recorded. The patients were allocated to groups of five, ranked according to the date of the operation. Operation duration, complications, postoperative length of stay, conversion to laparotomy and splenic weight were then compared between these groups.

RESULTS: There was a significant difference regarding operation times between the groups $(P=0.001)$. An improvement was observed after the first 5 cases. The learning curve was flat up to the 25th case. Following the 25th case the operation times decreased still further. There was no difference between the groups regarding the other parameters.

CONCLUSION: Unlike the widely accepted "L" shape, the learning curve for laparoscopic splenectomy is a horizontal lazy " $\mathrm{S}$ " with two distinct slopes. Privileges may be granted after the first 5 cases. However proficiency seems to require 25 cases. (c) 2009 The WJG Press and Baishideng. All rights reserved.

Key words: Laparoscopic splenectomy; Education; Learning curve; Hematology; Proficiency

Peer reviewer: Damian Casadesus Rodriguez, MD, PhD, Calixto Garcia University Hospital, J and University, Vedado, Havana City, Cuba

Nursal TZ, Ezer A, Belli S, Parlakgumus A, Caliskan K, Noyan T. Reaching proficiency in laparoscopic splenectomy. World $J$ Gastroenterol 2009; 15(32): 4005-4008 Available from: URL: http://www.wjgnet.com/1007-9327/15/4005.asp DOI: http:// dx.doi.org/10.3748/wjg.15.4005

\section{INTRODUCTION}

Laparoscopic splenectomy has become the gold standard intervention for the removal of the spleen, especially for benign causes. However, the organ's high anatomic location, fragility and generous blood supply makes the procedure an advanced laparoscopic operation ${ }^{[1,2]}$. Furthermore, unlike patients with gall bladder stones, patients who need splenectomy for benign disorders are rare. These factors may prohibit the laparoscopic surgeon from becoming proficient in laparoscopic splenectomy. Measuring the expertise and setting a minimum number of procedures to be performed in order to be accepted as proficient in this rather rare operation has proved difficult.

One method for quantifying the level of expertise is to split the study population arbitrarily into two, as early and late experience ${ }^{[3,4]}$. Several variables are then compared between the two groups. A more sensitive method is to depict the learning curve. The learning curve may be briefly defined as the repetition of the procedure until it is learned ${ }^{[5]}$. In this study, we aimed to define the learning curve for laparoscopic splenectomy based on the experience of a single surgeon.

\section{MATERIALS AND METHODS}

All patients with laparoscopically attempted splenectomy, operated on by a single surgeon (TZN), were included in this study. The time period was from November 2002 to January 2008. During this time span 33 patients (23 female) with a mean \pm SD age of $43.4 \pm 18.4$ years were operated. Operative indications were immune thrombocy- 
topenic purpura (ITP) $(n=27)$, hemolytic anemia $(n=3)$, thalassemia $(n=2)$, and hydatid cyst $(n=1)$. Besides demographics, associated disorders, the size of the spleen (long axis) as measured with preoperative ultrasonography, duration of surgery, the volume of gas used, additional procedures during operation, conversions to laparotomy, amount of intra/postoperative blood loss and blood products transfused, presence of accessory splenic tissue, complications, morsellated splenic weight, length of hospital stay, early and late success in hematological disorders and thrombocytosis in the long term were recorded.

Patients with hematological diseases were referred from the hematology clinic with resistant or persistent disease. The hydatid cyst patient had a type 3, 7-cm cyst in the spleen. He had percutaneous treatment for type 1 and 2 cysts located in the liver.

All patients received vaccination against encapsulated bacteria within 2 wk prior to operation. For ITP cases, the patients received pulse steroid or intravenous immunoglobulin therapy before the operation in order to increase the thrombocyte count to at least $50000 / \mathrm{mm}^{3}$. General anesthesia was used. A nasogastric tube was placed routinely. A lateral approach was used for the operation ${ }^{[6-8]}$. The patient was placed in a $70-80^{\circ}$ right lateral position with reverse Trendelenburg for the table. The table was flexed $20-25^{\circ}$ at the kidney rest to increase the left flank space. Following skin preparation and draping, the table was tilted to the left in order to obtain an approximately supine position for the initial insufflation. Four trocars, each $5 \mathrm{~cm}$ apart, were placed along an imaginary left subcostal incision with the most medial on the midline and most lateral on the left anterior axillary line. The table was again tilted to the original position. The $30^{\circ}$ optic was introduced through the middle of the lateral 3 trocars. The stomach was manipulated through the most medial 4th trocar. The dissection was started from the inferior pole using clips and ultrasonic dissector for vascular control. Hilar vessels were controlled in the same manner, sometimes utilizing intracorporeal silk ligatures for the large-sized vessels. A vascular stapler was not used routinely: it was deemed necessary for only one patient with large-sized vessels. Lastly, short gastric vessels were controlled. After separating the lateral connections, the spleen was placed in a retrieval bag and was morsellated and removed through the lateral $10 \mathrm{~mm}$ trocar. The piecemeal specimen was weighed and sent for pathological assessment.

Patients were usually started on oral feeding the next day and discharged or transferred to the hematology clinic the following day. Hemoglobin and thrombocyte counts were studied on the first postoperative week and 3 rd postoperative month to assess the early and late response to splenectomy for hematological diseases. Response to the surgery was defined as hemoglobin level greater than $100 \mathrm{~g} / \mathrm{L}$ for hemolytic anemia and thrombocyte count of more than $150000 / \mathrm{mm}^{3}$ for ITP. Thrombocytosis is defined as a thrombocyte count of more than $600000 / \mathrm{mm}^{3}$.

General descriptive characteristics of the group

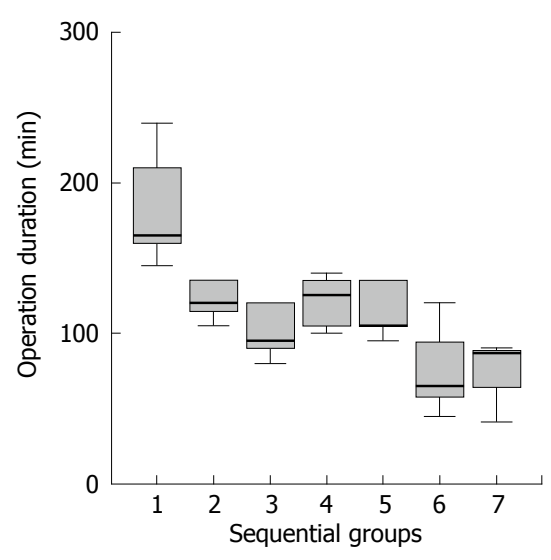

Figure 1 The learning curve for laparoscopic splenectomy based on the operation times. Groups are formed according to the date of the operation.

were expressed as mean \pm SD and percentages where necessary. In order to define the learning curve, patients were divided into groups of five ranked according to the date of operation (the last group consisted of 3 patients). Dichotomous variables such as rate of complications and conversion to laparotomy were compared between groups by $\chi^{2}$ analysis. Continuous variables such as the duration of operation, the amount of gas used, splenic weight and length of hospital stay between ranked groups were compared using the ANOVA technique. $P<0.05$ was accepted as significant. All analyses were performed using SPSS version 13.0 (SPSS, Chicago, Illionis).

\section{RESULTS}

In $18(54.5 \%)$ patients the size of the spleen was less than $12 \mathrm{~cm}$. The size was in the range of $12-20 \mathrm{~cm}$ in $14(42.4 \%)$ patients and over $20 \mathrm{~cm}$ in one patient $(3.0 \%)$. One third of the patients $(n=10)$ had additional systemic diseases, diabetes mellitus $(n=4)$ being the most common.

The immediate preoperative thrombocyte count for ITP cases was $60960 \pm 77440 / \mathrm{mm}^{3}$. Hemoglobin level for hemolytic anemia and thalassemia cases was $92 \pm 38 \mathrm{~g} / \mathrm{L}$.

Only one patient $(3 \%)$ was converted to laparotomy. In this patient (12th case, 3rd group) the spleen was large, over $20 \mathrm{~cm}$ and weighed $1040 \mathrm{~g}$. Hemorrhage could not be controlled and the case was converted at the 105th min. Erythrocyte suspension (5 units) was transfused to 3 hemolytic anemia patients (9.1\%) during the perioperative period. Thrombocyte transfusion was not needed.

The mean operation duration for the whole group was $120.2 \pm 46.2 \mathrm{~min}$. There was a significant difference between ranked groups regarding operation time $(P=$ 0.001). The last two groups' operation time, i.e. after the 25th case, was less than the first 5 cases according to the Bonferroni post hoc test (Figure 1).

Accessory spleens were detected and removed in 5 patients $(15.2 \%)$. The average amount of $\mathrm{CO}_{2}$ used was $137.5 \pm 80.7$ L. There was no difference between ranked groups regarding $\mathrm{CO}_{2}$ use $(P=0.119)$. Postoperative complications were observed in 3 patients (one atelectasis, 
one wound infection and one suture reaction). Early and late success rates were $83.9 \%$ and $81.0 \%$, respectively, and were not significantly different between the groups. Thrombocytosis was observed in 5 patients (15.2\%). Antiaggregant therapy with salicylic acid was instituted for these patients.

\section{DISCUSSION}

There has been a rush for minimal access surgery with the introduction of laparoscopic cholecystectomy in the 1980s. However, the surgical community was not technically prepared for this uncontrolled demand. Although weekend courses, seminars and hands-on courses were held worldwide, minimal access surgery education was less than optimal ${ }^{[9-11]}$. Surgical societies, not wishing to repeat these mistakes, started regular courses for both basic and advanced laparoscopic procedures. Universities and teaching hospitals included these procedures in their curricula. Several societies advocated a minimum number of procedures to be set to grant privileges to perform an operation ${ }^{[12]}$.

It is difficult to define a point when mastery of a procedure is reached. Subjective assessment in this regard is unreliable and several objective methods have been devised for this task. One simple method is to compare the early with late experience. For this, a chronologicallyranked patient population is divided in two ${ }^{[4]}$. Markers of expertise such as operation time, complication rate, conversion rates (in case of laparoscopy), time to oral feed and cost are then compared between these arbitrarily separated groups. The learning curve, which is more sensitive, usually is a graphic representation of the expertise level reached for a particular procedure/process. The cases are individually ranked on a chronological basis and are placed on one axis of the graph. The abovementioned variables are depicted on the other axis. The initial slope of the curve is usually steep where the learning process is fast and with each case performance increases. After a while, the slope flattens and no major improvement can be observed following a certain number of the procedures. The point, the nth case, where the curve starts to flatten is accepted as the instance where the procedure is learnt. Even after this point minor improvement in performance is detected, albeit the difference is usually not significant. A variation of this technique is to allocate patients into small groups and compare these groups with regard to determined variables. Similarly there is a point when a significant difference cannot be observed, which is accepted as the number of procedures needed to perform to reach proficiency.

Since the first report of laparoscopic splenectomy by Delaitre, this procedure has become the preferred treatment for the removal of the spleen ${ }^{[13-15]}$. However, this being one of the advanced laparoscopic procedures and due to the relatively rare occurrence of the conditions requiring splenectomy, the procedure is difficult to master.

Several studies have defined the minimum number of laparoscopic splenectomies to be performed for proficiency. Operation time is the most used variable as it is easier to calculate and validate. In the study by Rege and Joehl, these authors suggested that an improvement occurred with the first 15-25 patients ${ }^{[3]}$. In a review generally comparing the results of initial and late experience for laparoscopic procedures, it was determined that 20 laparoscopic splenectomies were sufficient for mastery ${ }^{[5]}$. In the study by Peters et al ${ }^{[16]}$, a minimum of 20 laparoscopic splenectomies were deemed necessary for ITP surgery proficiency. Regarding pediatric surgery, 20 cases, similarly, were declared to be the threshold for proficiency ${ }^{[17]}$.

However, there are some design limitations of the above-mentioned studies. In the reports by Rege and Chan the patient populations were split in two; an initial first 15 , and those that came later ${ }^{[3,4]}$. The cut-off point was chosen arbitrarily and compared only two groups, i.e. the initial and late experience, which may decrease the sensitivity as stated previously. Further, in order to document an accurate progress and exclude personal variations, the performance of a single surgeon should be recorded. If other surgeons' experiences are included, the investigated parameters may differ according to the individual's skill. Among the above-mentioned studies, the experience of a single surgeon was assessed in only one report ${ }^{[17]}$. Among the rest of the reports, either senior residents gradually started to perform the operations or different hospitals/surgeons were included in the analyses ${ }^{[3,16,18]}$. The concern about inclusion of low-volume surgeons in such assessments has also been previously stated ${ }^{[19,20]}$. Although Cordera et al ${ }^{[20]}$ have attempted some 42 laparoscopic splenectomies, rightfully they have not calculated a learning curve due to inclusion of several surgeons. Another potential source of bias is the introduction of new devices or technology during the study period. For instance, an ultrasonic dissector was introduced during the latter course of the study in one report ${ }^{[4]}$.

In our study the experience of a single surgeon was assessed to exclude personal variations in skill. In order to eliminate the possible confounding effects of the mechanical set-up, standard techniques and instruments were used during the course of the study. Instead of comparing the arbitrary initial and late experience we have assessed the differences between sequential multiple groups. Twenty to twenty-five laparoscopic splenectomies were cited to be the minimum number for mastery of the procedure in the literature. However, it is common knowledge that privileges are granted with far less experience of this relatively rare operation. Usually 3 to 5 laparoscopic splenectomies, arbitrarily defined, are accepted to be sufficient ${ }^{[3]}$. However, there is no evidence in the literature supporting this figure. We provide the first evidence that 5 laparoscopic splenectomies could be accepted as the minimum number for the general curricula. There is a dual curve in our study of the learning process (Figure 1). Progress is rapid with the first 5 cases and then the curve steadies up to the 25 th case. At that point there is again a significant increase in the performance i.e. a decrease in the operation time.

We have shown that the learning curve for laparo- 
scopic splenectomy is not a smooth " $L$ " but has two distinct slopes. With the first 5 cases the novice may be granted privileges for performing laparoscopic splenectomy on an individual basis. Past the 25th case the surgeon could be accepted as an expert in the field. Although unlikely, it is yet to be shown that any further improvement could be observed after this level.

\section{COMMENTS}

\section{Background}

Laparoscopic revolution resulted in some controversies regarding the education in advanced laparoscopic surgery. In order to assess the level of expertise and to grant privileges in surgery, a learning curve of the procedure is used.

\section{Research frontiers}

Laparoscopic splenectomy has become the gold standard intervention for the removal of the spleen, especially for benign causes. In this study, the authors have investigated the proficiency level reached in laparoscopic splenectomy using the learning curve method.

\section{Innovations and breakthroughs}

Unlike the widely accepted "L" shape, the learning curve for laparoscopic splenectomy is a horizontal lazy "S" with two distinct slopes. Privileges may be granted after the first 5 cases. However, proficiency seems to require 25 cases.

\section{Applications}

The authors have shown that the learning curve for laparoscopic splenectomy is not a smooth "L" but has two distinct slopes. With the first 5 cases the novice may be granted privileges for performing laparoscopic splenectomy on an individual basis. Past the 25 th case the surgeon could be accepted as an expert in the field.

\section{Terminology}

The learning curve is a graphic representation of the expertise level reached for a particular procedure. This is briefly defined as the repetition of the procedure until it is learned. Reaching proficiency is defined by measuring the expertise and setting a minimum number of procedures to be performed in order to be accepted as proficient.

\section{Peer review}

It is an interesting topic for the readers. It should be accepted for publication.

\section{REFERENCES}

1 Casaccia M, Torelli P, Squarcia S, Sormani MP, Savelli A, Troilo B, Santori G, Valente U. Laparoscopic splenectomy for hematologic diseases: a preliminary analysis performed on the Italian Registry of Laparoscopic Surgery of the Spleen (IRLSS). Surg Endosc 2006; 20: 1214-1220

2 Brodsky JA, Brody FJ, Walsh RM, Malm JA, Ponsky JL. Laparoscopic splenectomy. Surg Endosc 2002; 16: 851-854

3 Rege RV, Joehl RJ. A learning curve for laparoscopic splenectomy at an academic institution. J Surg Res 1999; 81: 27-32

4 Chan SW, Hensman C, Waxman BP, Blamey S, Cox J, Farrell K, Fox J, Gribbin J, Layani L. Technical developments and a team approach leads to an improved outcome: lessons learnt implementing laparoscopic splenectomy. ANZ J Surg

\section{2; 72: 523-527}

5 Dagash H, Chowdhury M, Pierro A. When can I be proficient in laparoscopic surgery? A systematic review of the evidence. J Pediatr Surg 2003; 38: 720-724

6 Tan M, Zheng CX, Wu ZM, Chen GT, Chen LH, Zhao ZX. Laparoscopic splenectomy: the latest technical evaluation. World J Gastroenterol 2003; 9: 1086-1089

7 Katkhouda N, Hurwitz MB, Rivera RT, Chandra M, Waldrep DJ, Gugenheim J, Mouiel J. Laparoscopic splenectomy: outcome and efficacy in 103 consecutive patients. Ann Surg 1998; 228: 568-578

8 Chu UB, Park A, Mastrangelo MJ. Laparoscopic splenectomy. Curr Surg 2001; 58: 63-67

9 Esposito C, Schaarschmidt K, Settimi A, Montupet P. Experience with laparoscopic splenectomy. J Pediatr Surg 2001; 36: 309-311

10 Reynolds FD, Goudas L, Zuckerman RS, Gold MS, Heneghan S. A rural, community-based program can train surgical residents in advanced laparoscopy. J Am Coll Surg 2003; 197: 620-623

11 Rogers DA, Elstein AS, Bordage G. Improving continuing medical education for surgical techniques: applying the lessons learned in the first decade of minimal access surgery. Ann Surg 2001; 233: 159-166

12 Society of American Gastrointestinal and Endoscopic Surgeons (SAGES). Guidelines for Institutions Granting Privileges Utilizing Laparoscopic and/or Thoracoscopic Techniques. 2001. Available from: URL: http://sages.org/ publication/id/14/

13 Bagdasarian RW, Bolton JS, Bowen JC, Fuhrman GM, Richardson WS. Steep learning curve of laparoscopic splenectomy. J Laparoendosc Adv Surg Tech A 2000; 10: 319-323

14 Rosen M, Brody F, Walsh RM, Tarnoff M, Malm J, Ponsky J. Outcome of laparoscopic splenectomy based on hematologic indication. Surg Endosc 2002; 16: 272-279

15 Delaitre B, Maignien B. Laparoscopic splenectomy-technical aspects. Surg Endosc 1992; 6: 305-308

16 Peters MB Jr, Camacho D, Ojeda H, Reichenbach DJ, Knauer EM, Yahanda AM, Cooper SE, Sweeney JF. Defining the learning curve for laparoscopic splenectomy for immune thrombocytopenia purpura. Am J Surg 2004; 188: 522-525

17 Cusick RA, Waldhausen JH. The learning curve associated with pediatric laparoscopic splenectomy. Am J Surg 2001; 181: 393-397

18 Pomp A, Gagner M, Salky B, Caraccio A, Nahouraii R, Reiner M, Herron D. Laparoscopic splenectomy: a selected retrospective review. Surg Laparosc Endosc Percutan Tech 2005; 15: 139-143

19 Pace DE, Chiasson PM, Schlachta CM, Mamazza J, Poulin EC. Laparoscopic splenectomy does the training of minimally invasive surgical fellows affect outcomes? Surg Endosc 2002; 16: 954-956

20 Cordera F, Long KH, Nagorney DM, McMurtry EK, Schleck C, Ilstrup D, Donohue JH. Open versus laparoscopic splenectomy for idiopathic thrombocytopenic purpura: clinical and economic analysis. Surgery 2003; 134: 45-52

S- Editor Li LF L- Editor Logan S E- Editor Lin YP 